\title{
The Competition of Charge Remote and Charge Directed Fragmentation Mechanisms in Quaternary Ammonium Salt Derivatized Peptides-An Isotopic Exchange Study
}

\author{
Marzena Cydzik, Magdalena Rudowska, Piotr Stefanowicz, Zbigniew Szewczuk
}

Faculty of Chemistry, University of Wrocław, F. Joliot-Curie 14, 50-383 Wrocław, Poland

\begin{abstract}
Derivatization of peptides as quaternary ammonium salts (QAS) is a promising method for sensitive detection by electrospray ionization tandem mass spectrometry (Cydzik et al. J. Pept. Sci. 2011, 17, 445-453). The peptides derivatized by QAS at their N-termini undergo fragmentation according to the two competing mechanisms - charge remote $(\mathrm{ChR})$ and charge directed (ChD). The absence of mobile proton in the quaternary salt ion results in ChR dissociation of a peptide bond. However, Hofmann elimination of quaternary salt creates an ion with one mobile proton leading to the ChD fragmentation. The experiments on the quaternary ammonium salts with deuterated $\mathrm{N}$-alkyl groups or amide $\mathrm{NH}$ bonds revealed that QAS derivatized peptides dissociate according to the mixed ChR-ChD mechanism. The isotopic labeling allows differentiation of fragments formed according to $\mathrm{ChR}$ and $\mathrm{ChD}$ mechanisms.
\end{abstract}

Key words: Quaternary ammonium salts, Derivatization of peptides, Peptide sequencing

\section{Introduction}

A tructural characterization of molecules by mass spec$\checkmark$ trometry relies on the fragmentation of precursor ions during the analysis, yielding a variety of structurally significant fragment ions [1]. There are two distinct fragmentation pathways of protonated peptides, based on charge-directed $(\mathrm{ChD})$ and charge-remote (ChR) mechanisms. $\mathrm{ChD}$ reactions occur for peptides containing a proton attached to amino group. The proton is mobile and can migrate from one protonation site to another [2-4]. The protonation of amide nitrogen weakens the amide bond, resulting in fragmentation of the peptide backbone after gas-phase collisional activation [5].

Electronic supplementary material The online version of this article (doi:10.1007/s13361-011-0245-2) contains supplementary material, which is available to authorized users.

Correspondence to: Zbigniew Szewczuk; e-mail: zbigniew.szewczuk@chem. uni.wroc.pl
The first examples of ChR fragmentation were observed during a study of fatty acids [6]. For peptides, the ChR processes occur when the charge is fixed on one particular atom, e.g., at arginine residue, which has high proton affinity [7-9]. The effect of arginine residue can be mimicked by derivatizing a peptide with a fixed positive charge-carrying molecule, including quaternary ammonium salts (QAS) [10]. The ChR fragmentation does not depend on the mobile proton but it is rather caused by the intramolecular hydrogen shifting within the precursor ion. To pinpoint which of the hydrogens ( $\alpha, \beta$, and amide) is involved in the mechanism, peptide derivatives with selective deuterium labeling were analyzed [11, 12]. The results suggest that it is the amide hydrogen of the residue at which the cleavage occurs that shifts during the fragmentation. Previously, Reid et al. described the competition of both fragmentation pathways during ESI-MS/MS experiment using protonated serine and its derivatives [13]. To the best of our knowledge, the coexistence of both mechanisms during the fragmentation of 
the nonprotonated $[\mathrm{M}]^{+}$molecular ion of QAS-peptide derivatives has not been reported.

Recently, we presented a new method of derivatization of peptides as QAS on solid support [14]. The proposed methodology offers a novel approach to increase sensitivity in analysis of peptides by electrospray ionization tandem mass spectrometry. In this study, we present the fragmentation pathways of model peptides conjugated with various linear QAS. We performed ESI-MS/MS experiments on $[\mathrm{M}]^{+}$ions of all the synthesized QAS-peptide derivatives. With the aid of deuterium-labeled analogs the contribution of two known distinct fragmentation pathways, charge-directed and charge-remote mechanisms, was examined using collision-induced dissociation (CID).

\section{Experimental}

\section{Materials}

The details of performed syntheses are given as Supplementary Data.

\section{Hydrogen/Deuterium Exchange}

H/D exchange was initiated by dissolving $0.1 \mathrm{mg}$ of QASpeptide derivatives in $200 \mu \mathrm{L}$ of $\mathrm{D}_{2} \mathrm{O}$ at room temperature. After $20 \mathrm{~min}$, all protons from the amide bonds and amino acid side chains were exchanged for deuterons, as judged from the ESI-MS analysis.

\section{Mass Spectrometry}

All experiments were performed on a Fourier transform ion cyclotron resonance (FT-ICR) Apex-Qe Ultra 7T instrument (Bruker Daltonics, Bremen, Germany). The instrumental settings and measurement details are described in Supplementary Data.

\section{Results and Discussion}

To investigate the influence of QAS on the mechanism of peptide fragmentation we synthesized on solid phase a series of model tetrapeptides containing four different QAS: trimethyl-, triethyl-, tripropyl- and tributyl-ammonium acetyl (TMAA, TEAA, TPAA, TBAA, respectively) derivatized peptides (Table 1S in Supplementary Data). We performed ESI-MS/MS experiments on $[\mathrm{M}]^{+}$ions of all the synthesized QAS-peptide derivatives. As we indicated in our previous article [14], a series of fragment ions $\left[\mathrm{a}-\mathrm{C}_{2} \mathrm{H}_{4}\right]$ and $\left[\mathrm{b}-\mathrm{C}_{2} \mathrm{H}_{4}\right]$ for TEAA, $\left[\mathrm{a}-\mathrm{C}_{3} \mathrm{H}_{6}\right]$ and $\left[\mathrm{b}-\mathrm{C}_{3} \mathrm{H}_{6}\right]$ for TPAA, and $\left[\mathrm{a}-\mathrm{C}_{4} \mathrm{H}_{8}\right]$ and $\left[\mathrm{b}-\mathrm{C}_{4} \mathrm{H}_{8}\right]$ for TBAA peptides derivatives were observed as the consequence of partial QAS group fragmentation by Hofmann elimination (Supplementary Data, Figure 2S). The
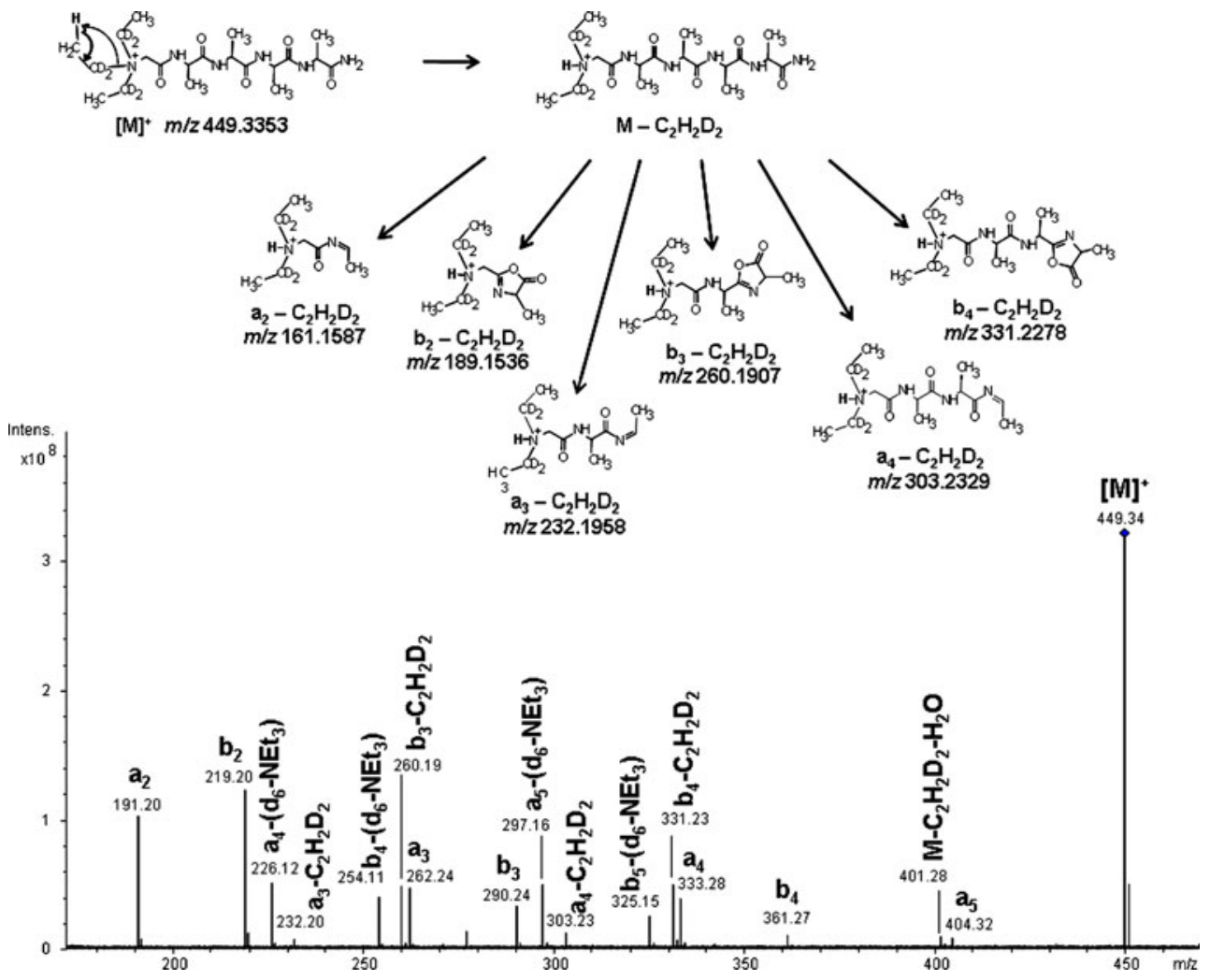

Figure 1. ESI MS/MS spectrum of the $[\mathrm{M}]^{+}$molecular ion of peptide $\left(\mathbf{d}_{\mathbf{6}}-\mathbf{E t}_{\mathbf{3}} \mathbf{N}\right)-\mathbf{1} \mathbf{b}$. Neutral losses of the alkene molecule from $\left(\mathbf{d}_{\mathbf{6}}-\mathrm{Et}_{\mathbf{3}} \mathbf{N}\right)-\mathbf{1 b}$ and its $\mathrm{a}$ - and $\mathrm{b}$-fragment ions resulting from Hofmann elimination are presented (theoretical values of $m / z$ are given) 
neutral loss of the alkene molecule $\left(\mathrm{C}_{n} \mathrm{H}_{2 n}\right)$ results in appearance of a mobile proton in the QAS-derivatized peptide ion, which was further used for studying the hydrogen scrambling in deuterated peptide ions.
The aim of our study was to prove whether the hydrogen atom located at the 1' or the 2' carbon atom of the QAS alkyl group participates in the Hofmann elimination. We synthesized two TEAA peptide derivatives with deuterons located (a)

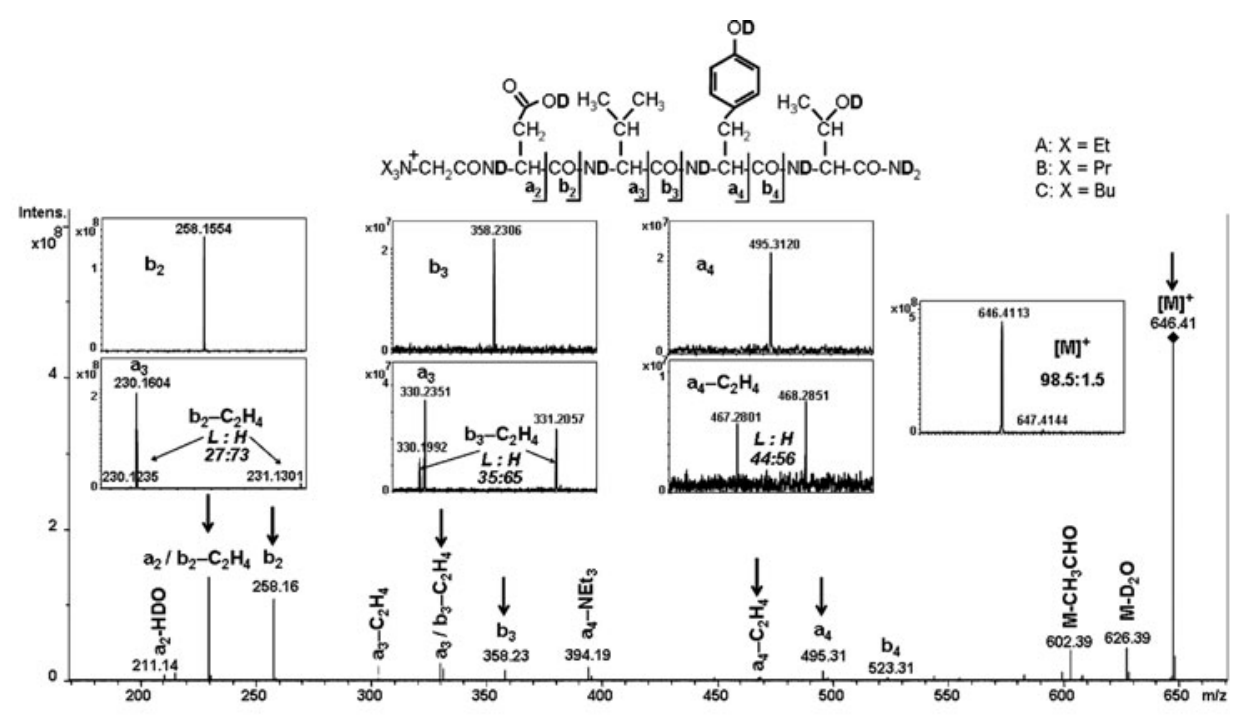

(b)
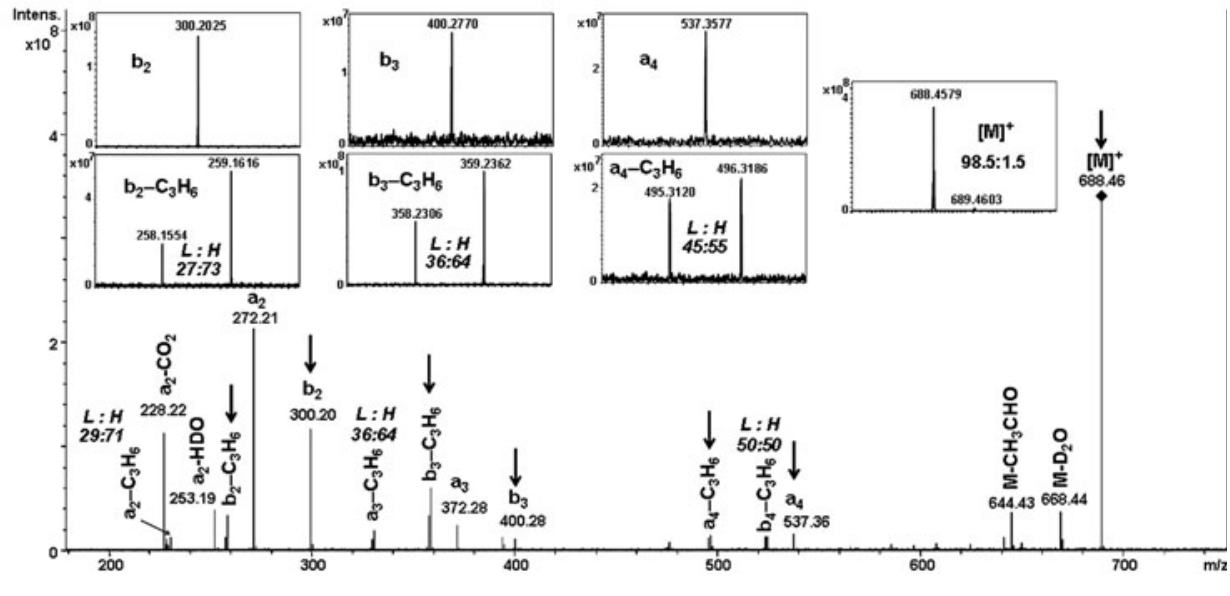

(c)

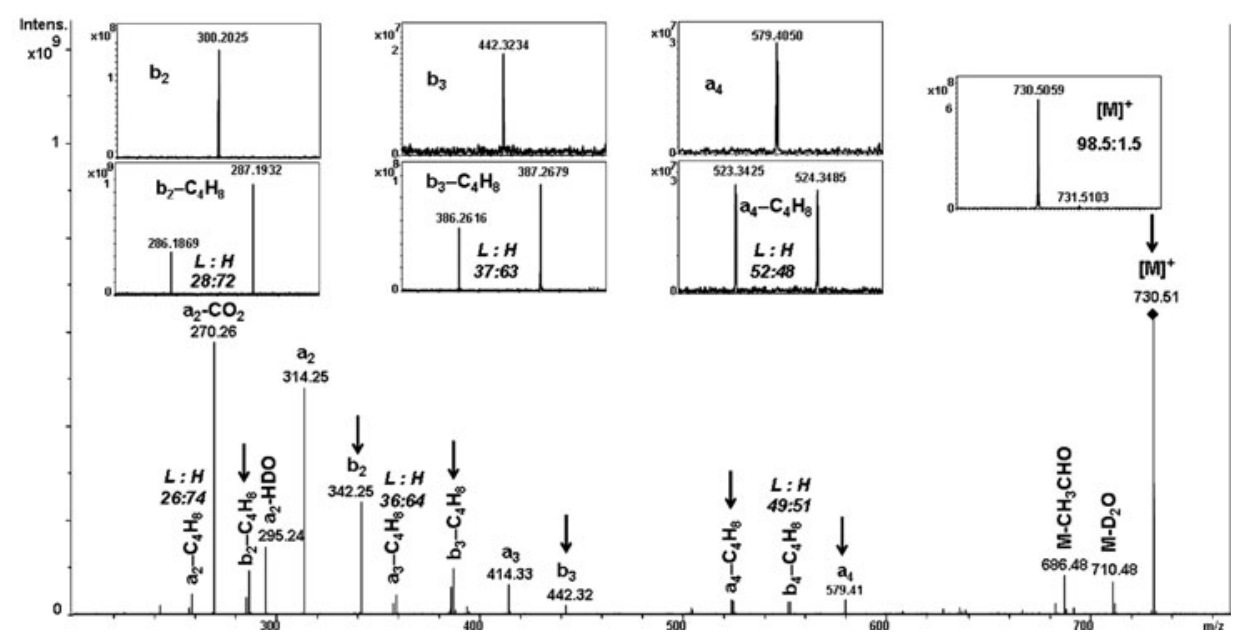

Figure 2. ESI-MS/MS spectra of deuterated QAS-peptides. (a) $d_{\mathbf{g}} \mathbf{- 1 b}, X=E t$, (b) $d_{\mathbf{g}}-\mathbf{1 c}, X=\operatorname{Pr}$, and (c) $d_{\mathbf{g}}-\mathbf{1 d}, X=B u$. The peaks of representative fragments ( $L$ and $H$ peaks) are shown in insets. ESI-MS/MS spectra for other deuterated QAS-peptides and ratios of $\mathrm{L}$ and $\mathrm{H}$ peak intensities for all QAS-peptides are presented in Supplementary Data (Figures 4-6S and Table 2S) 
at the 1' carbon atoms of N-alkyl groups of QAS $\left(\mathrm{d}_{6}-\mathrm{Et}_{3} \mathrm{~N}^{+}\right.$$\left.\mathrm{CH}_{2} \mathrm{CO}-\mathrm{Asp}-\mathrm{Val}-\mathrm{Tyr}-\mathrm{Thr}-\mathrm{NH}_{2} \quad\left(\mathbf{d}_{\mathbf{6}}-\mathbf{E t}_{\mathbf{3}} \mathbf{N}\right)-\mathbf{1 b}\right), \mathrm{d}_{6}-\mathrm{Et}_{3} \mathrm{~N}^{+}-$ $\mathrm{CH}_{2} \mathrm{CO}$-Ala-Ala-Ala-Ala-NH $\left.\mathrm{N}_{2}\left(\left(\mathbf{d}_{\mathbf{6}}-\mathbf{E t}_{\mathbf{3}} \mathbf{N}\right)-\mathbf{5 b}\right)\right)$. For this purpose we developed a new method of the synthesis of QAS-peptides on solid support by direct N-alkylation of the amino group by deuterated ethyl iodide $\mathrm{CH}_{3} \mathrm{CD}_{2} \mathrm{I}$.

The representative MS/MS spectrum of the parent ion $[\mathrm{M}]^{+}$for peptide $\left(\mathbf{d}_{\mathbf{6}}-\mathbf{E t}_{\mathbf{3}} \mathbf{N}\right)-\mathbf{1 b}$ is presented in Figure 1. The analysis reveals a series of b-type ions, ranging from $b_{2}$ to $\mathrm{b}_{4}$, accompanied by the corresponding a-type ions. A series of a- and b-fragment ions with neutral losses of 30.0439 were observed as the consequence of $\mathrm{C}_{2} \mathrm{H}_{2} \mathrm{D}_{2}$ elimination from the QAS group. A similar fragmentation pathway was also observed for the second synthesized deuterated peptide, $\left(\mathbf{d}_{\mathbf{6}}-\mathbf{E t}_{\mathbf{3}} \mathbf{N}\right)-\mathbf{5 b}$ (Supplementary Data, Figure 3S). The neutral loss of $\mathrm{C}_{2} \mathrm{H}_{2} \mathrm{D}_{2}$ rather than $\mathrm{C}_{2} \mathrm{H}_{3} \mathrm{D}$ indicates that it is the proton from methyl, not methylene group which is left on nitrogen after Hofmann elimination of the ethylene. This mobile proton can then migrate to amide groups of peptide backbone thus allowing the $\mathrm{ChD}$ fragmentation mechanism (Figure 1).

\section{ESI-MS/MS Analysis of Deuterated QAS-Peptide Derivatives}

To check the contribution of two fragmentation pathways, $\mathrm{ChD}$ and $\mathrm{ChR}$, during fragmentation of the QAS-peptides, we obtained a series of derivatives (Table $1 \mathrm{~S}$ in Supplementary
Data) and replaced all exchangeable protons by deuterons. Therefore, in ChR mechanism, the amide deuteron should contribute to the fragment formation. On the other hand, the $\mathrm{ChD}$ fragmentation pathway may occur when a proton is transferred from the 2' carbon atom of the $\mathrm{N}$-alkyl group of a QAS-residue during Hofmann elimination in the initial alkene loss during CID.

We performed the ESI-MS/MS analysis on the monoisotopic ion of the deuterated precursor to determine the participation of both mechanisms. Figure 2c presents a high resolution ESI-MS/MS spectrum of peptide $\mathbf{d}_{\mathbf{9}} \mathbf{- 1 d}$, with all exchangeable protons substituted by deuterons. The parent ion $[\mathrm{M}]^{+}$selected for fragmentation contains specific species of $\mathbf{d}_{\mathbf{g}}-\mathbf{1 d}$, with negligible amount (less than $2 \%$ ) of molecules containing ${ }^{13} \mathrm{C}$ atoms. Therefore, the intensity ratio of isotopic peaks of the resulting fragments that differ from each other by one $\mathrm{Da}$ depends on the contribution of protons and deuterons (assigned as $\mathrm{L}$ and $\mathrm{H}$ peaks) but not contribution of ${ }^{13} \mathrm{C}$ atoms. The obtained results indicate that the formation of a- and b-ions (without neutral losses) occurs with amide deuteron shift, since the formed fragments were represented by single peaks [Figure 2c (insets)]. This strongly supports the ChR fragmentation mechanism during formation of a- and b-ions. In contrast, all fragment ions [a$\left.\mathrm{C}_{4} \mathrm{H}_{8}\right]$ and $\left[\mathrm{b}-\mathrm{C}_{4} \mathrm{H}_{8}\right]$ are represented by pairs of peaks, differing by one mass unit. The peak, located at higher $\mathrm{m} / \mathrm{z}$ (H) corresponds to the fragment with all protons exchanged by

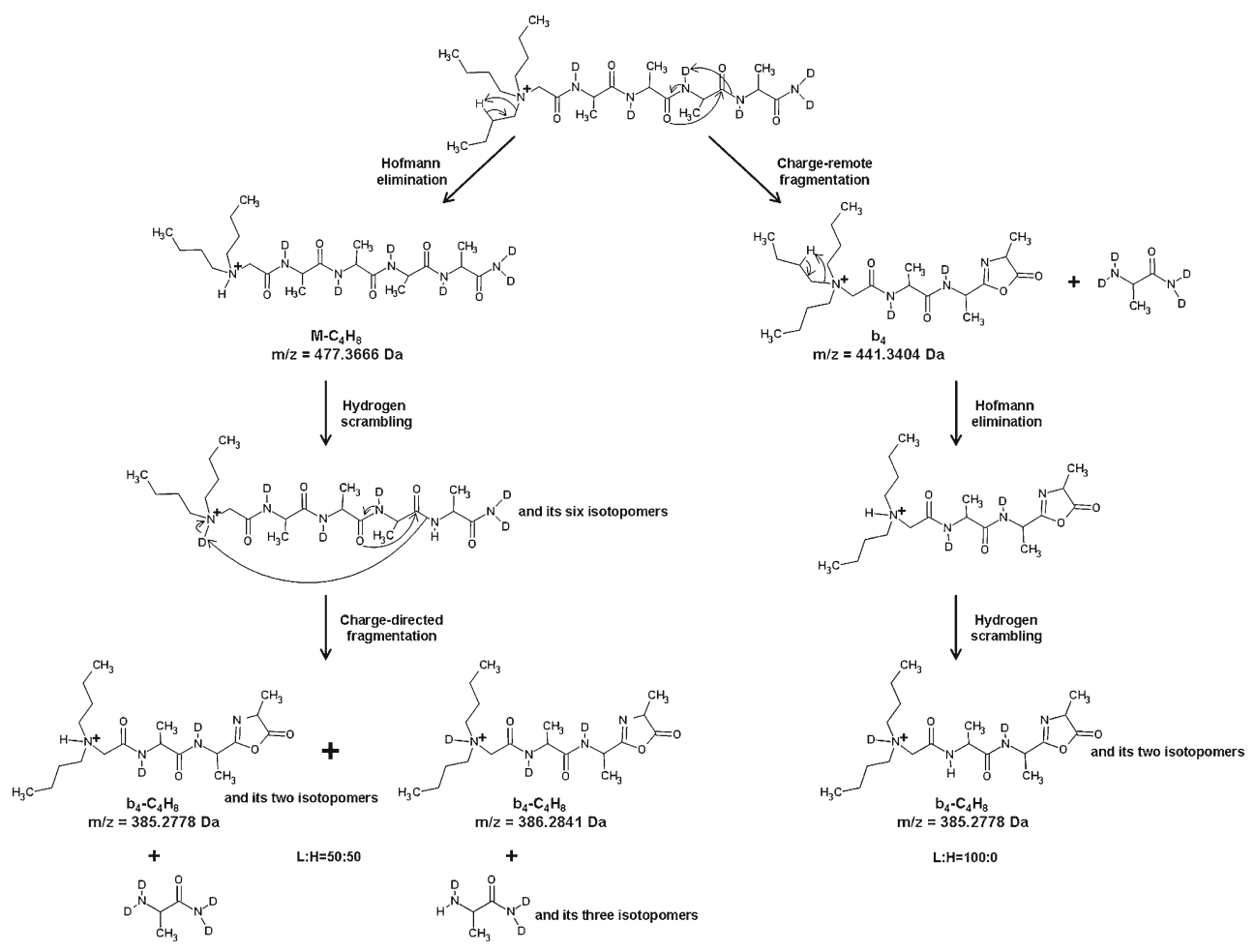

Figure 3. Two possible pathways of $\mathbf{b}_{4}-\mathrm{C}_{4} \mathrm{H}_{8}$ formation from $\mathbf{d}_{6}-\mathbf{5 d}$ precursor ion. Theoretical $\mathrm{m} / z$ values and intensity ratios of $\mathrm{L}$ and $\mathrm{H}$ peaks are given 
deuterons, whereas the second one, located at lower $m / z$ (L), represents the fragment with one remaining proton.

The presence of both isotopic $\mathrm{L}$ and $\mathrm{H}$ peaks may be explained assuming that Hofmann elimination (Figure 1) results in formation of a protonated peptide, which therefore undergoes the $\mathrm{ChD}$ fragmentation according to the mobile proton model [15], with fast intramolecular proton exchange (hydrogen scrambling) and peptide bond dissociation initiated by protonation. The ion of analyzed peptide $\mathbf{d}_{\mathbf{g}}-\mathbf{1 d}$ possesses nine exchangeable deuterons (Figure 2c). Hofmann elimination results in protonation of an alkylated $\mathrm{N}$-terminal nitrogen. As a result, the $\left[\mathrm{M}-\mathrm{C}_{4} \mathrm{H}_{8}\right]$ ion contains nine deuterons and one proton. Assuming that the hydrogen scrambling is not impaired, each protonation site contains $90 \% \mathrm{D}$ and $10 \% \mathrm{H}$. Therefore, the intensities of $\mathrm{L}$ and $\mathrm{H}$ peaks should depend on the number of available sites in consecutive fragment ions. For example, the $\left[\mathrm{a}_{4}-\mathrm{C}_{4} \mathrm{H}_{8}\right]$ fragment retains five protonation sites from $\left[\mathrm{M}-\mathrm{C}_{4} \mathrm{H}_{8}\right](50 \%)$, therefore, the expected $\mathrm{L}: \mathrm{H}$ ratio is 50:50. This value is in good agreement with the experimental L:H peak ratio (52:48). The experimental proton contents for $\left[\mathrm{b}_{3}-\mathrm{C}_{4} \mathrm{H}_{8}\right]$ and $\left[\mathrm{b}_{2}-\mathrm{C}_{4} \mathrm{H}_{8}\right]$ ions (37\% and $27 \%$ ) were slightly higher as compared to the calculated ones $(30 \%$ and $20 \%$, respectively). One of the possible explanations of this phenomenon is that $b-\mathrm{C}_{4} \mathrm{H}_{8}$ ions ( $\mathrm{L}$ and $\mathrm{H}$ ) may be formed from $\mathbf{d}_{\mathbf{g}}-\mathbf{1 d}$ precursor according to two parallel fragmentation pathways. The first one is based on the described above assumption that after the initial Hofmann elimination the proton located at the N-terminal nitrogen participates in hydrogen scrambling with deuterated amides of peptide backbone. The following $\mathrm{ChD}$ fragmentation leads to two $\mathrm{b}_{4}-\mathrm{C}_{4} \mathrm{H}_{8}$ ions represented by $\mathrm{L}$ and $\mathrm{H}$ peaks, since the discussed proton may remain in the $\mathrm{b}_{4}-\mathrm{C}_{4} \mathrm{H}_{8}$ fragment or in the neutral $\mathrm{C}$-terminal fragment. The alternative pathway leading to the $\mathrm{b}-\mathrm{C}_{4} \mathrm{H}_{8}$ ions may be initiated by $\mathrm{ChR}$ fragmentation of the $\mathbf{d}_{\mathbf{9}}-\mathbf{1 d}$ precursor, with the proceeding Hofmann elimination. The second pathway may only produce proton-containing $\mathrm{b}$-fragments (represented by $\mathrm{L}$ peaks), as the cleavage of amide bond occurs before the proton from Hofmann elimination is available for scrambling.

Similar results were obtained for other tested QAS-peptide derivatives (supplementary data, Figures 4-6S), which indicates that neither the carboxyl group of aspartic acid side chain nor the hydroxyl groups of tyrosine and threonine residues seem to affect the fragmentation pathways. The scheme of proposed fragmentation pathways for a representative peptide $\mathbf{d}_{\mathbf{6}} \mathbf{- 5 d}$ is presented in Figure 3.

\section{Conclusions}

Peptides derivatized with quaternary ammonium salts are characterized by a high ionization efficiency, which allows a sensitive mass spectrometric detection of these compounds. The fragmentation spectra are dominated by a- and b-type ions, with abundant neutral losses corresponding to Hofmann elimination. The use of isotopic labeling allows the identification of contributions of the $\mathrm{ChR}$ and $\mathrm{ChD}$ mechanisms to the fragmentation of QAS-derivatized peptides. The mobile proton required for $\mathrm{ChD}$ fragmentation ion is generated from Hofmann elimination of ammonium salt, which creates a convenient model for studying hydrogen scrambling in peptide ions.

\section{Acknowledgments}

The authors acknowledge support for this work by grant no. N N204 180040 from the Ministry of Science and Higher Education of Poland.

\section{Open Access}

This article is distributed under the terms of the Creative Commons Attribution Noncommercial License which permits any noncommercial use, distribution, and reproduction in any medium, provided the original author(s) and source are credited.

\section{References}

1. Hunt, D.F., Yates, J.R., Shabanowitz, J., Winston, S., Hauer, C.R.: Protein sequencing by tandem mass spectrometry. Proc. Natl. Acad. Sci. U.S.A. 83, 6233-6237 (1986)

2. Tsaprailis, G., Nair, H., Somogyi, A., Wysocki, V.H., Zhong, W., Futrell, J.H., Summerfield, S.G., Gaskell, S.J.: Influence of secondary structure on the fragmentation of protonated peptides. J. Am. Chem. Soc. 121, 5142-5154 (1999)

3. Paizs, B., Suhai, S.: Fragmentation pathways of protonated peptides. Mass Spectrom. Rev. 24, 508-548 (2005)

4. Dongre, A.R., Jones, J.L., Somogyi, A., Wysocki, V.H.: Influence of peptide composition, gas-phase basicity, and chemical modification on fragmentation efficiency: Evidence for the mobile proton model. J. Am. Chem. Soc. 118, 8365-8374 (1996)

5. McCormack, A.L., Somogyi, A., Dongre, A.R., Wysocki, V.H.: Fragmentation of protonated peptides: Surface-induced dissociation in conjunction with a quantum mechanical approach. Anal. Chem. 65, 2859-2872 (1993)

6. Tomer, K.B., Crow, F.W., Gross, M.L.: Location of double bond position in unsaturated fatty acids by negative ion MS/MS. J. Am. Chem. Soc. 105, 5487-5488 (1983)

7. Cheng, C., Gross, M.L.: Applications and mechanisms of charge-remote fragmentation. Mass Spectrom. Rev. 19, 398-420 (2000)

8. Adams, J.: Charge-remote fragmentations: Analytical applications and fundamental studies. Mass Spectrom. Rev. 9, 141-186 (1990)

9. Syrstad, E.A., Turecek, F.: Toward a general mechanism of electron capture dissociation. J. Am. Soc. Mass Spectrom. 16, 208-224 (2005)

10. Zaia, J., Biemann, K.: Comparison of charged derivatives for high energy collision-induced dissociation tandem mass spectrometry. J. Am. Soc. Mass Spectrom. 6, 428-436 (1995)

11. Liao, P.C., Huang, Z.H., Allison, J.: Charge remote fragmentation of peptides following attachment of a fixed positive charge: A matrixassisted laser desorption/ionization post-source decay study. J. Am. Soc. Mass Spectrom. 8, 501-509 (1997)

12. Sadagopan, N., Watson, J.T.: Mass spectrometric evidence for mechanism of fragmentation of charge-derivatized peptides. J. Am. Soc. Mass. Spectrom. 12, 399-409 (2001)

13. Reid, G.E., Simpson, R.J.: Leaving group and gas phase neighboring group effects in the side chain losses from protonated serine and its derivatives. J. Am. Soc. Mass Spectrom. 11, 1047-1060 (2000)

14. Cydzik, M., Rudowska, M., Stefanowicz, P., Szewczuk, Z.: Derivatization of peptides as quaternary ammonium salts for sensitive detection by ESI-MS. J. Pept. Sci. 17, 445-453 (2011)

15. Laskin, J., Lifshitz, C.: Principles of Mass Spectrometry Applied to Biomolecules. Wiley, New Jersey (2006) 